\title{
The phytotoxicity of 2,4,6-Trichlorophenol and Phenol to local agricultural plant species in China
}

\author{
K. Poon, K. L. Hon \& J. J. Huang \\ Food Science and Technology Program, \\ Division of Science and Technology, Beijing Normal University - Hong \\ Kong Baptist University United International College, China
}

\begin{abstract}
Industrial pollutants are known to affect the growth of plants and increase the costing of agricultural production. For ecological risk assessment, the toxicological screening benchmark concentrations of contaminants in soil and soil solution may use as the indicators for potential concern. The benchmark values were derived from the lowest values of the $\mathrm{EC}_{30}$ of the chemicals in tested plant species. As the economically important agricultural plant species in China are quite different from that of the North America, local data on the phytotoxicity of chemicals to local species should be a piece of valuable information. In the present studies, the method of seed germination and root elongation were used to estimate the $\mathrm{EC}_{50}$ and $\mathrm{EC}_{30}$ of 2,4,6-Trichlorophenol (TCP) and Phenol to six economically important local agricultural plants. The lowest $\mathrm{EC}_{30}$ of TCP in tested species was found to be one forth of the reference benchmark values, while the lowest $\mathrm{EC}_{30}$ of Phenol was similar to the benchmark concentration. The phytotoxicity of TCP was found to be more rigorous than that of Phenol in reducing the growth of local agricultural plants. For the tested agricultural species, Raphanus sativus "short-leave radish no. 13" was relatively insensitive to the effect of TCP and Phenol, while Amaranthus mangostanus "round-leaf green amaranth" was the most sensitive one. For the three species from the genus Brassica, they have similar sensitivity to both of the chemicals.

Keywords: 2,4,6-Trichorophenol, Phenol, phytotoxicity, toxicological benchmarks, agricultural plants.
\end{abstract}




\section{Introduction}

There is a rapid industrialization and soaring rise of urban population in China. Local environment is gradually contaminated with different chemicals released by industries [2-4]. A lot of environmental contaminants are known to have phytotoxic effects to the terrestrial plants [5-7]. Small organic molecules with molecular weight less than 500 can enter the plant root system easily. In most cases, plants do not have a defence system to discriminate the entry of these harmful organic materials [1] and the entry is largely determined on the basis of their polarity [1]. A lot of chemical pollutants have been demonstrated to affect the growth of terrestrial plants and increases the cost of agricultural production. Some of these contaminants could even accumulate in the plant and pass to human through consumption [8-9]. This imposes the potential food safety hazard to the public.

Environmental contaminant for example phenolic compounds were quite toxic and shown to damage DNA of human lymphocytes [4]. They are found in food, water and air. Phenol has been widely used in industry for example to produce pesticide and dyestuff. A lot of phenol-containing products were found in market including mouthwashes, toothache drops, throat lozenges, analgesic rubs, and antiseptic lotions or smoking tobacco [2]. These products could contribute part of the source of phenol contamination to environment. 2,4,6trichlorophenol (TCP) is a chlorinated phenol that has been used as a fungicide, herbicide, insecticide, antiseptic [10], defoliant, and glue preservative [11]. Upon heating, TCP decomposes to toxic and corrosive chemical, hydrogen chloride and chlorine [12]. Phenol and TCP have been demonstrated to inhibit the growth of root of Chinese cabbage [5].

The concern has been raised in media on the pace of development in China has gone far more advanced than the local policies and regulatory guidelines [13]. Constant monitoring and proper follow-up are necessary to control the influence of the industrial contaminants to agricultural production. According to the ecological risk assessment in US, wherever the land contain the contaminant of concentration over the toxicological screening benchmark are required for further attention [1]. However, there is not enough local data to support whether the toxicological screening benchmarks could be applicable to local agricultural plant species in China. In this present studies, we would like to gather more basic information on the phytotoxicity of industrial contaminants to local agricultural plant species of China in particular to the economically significant species. Six commonly consumed vegetables in south China were chosen for the studies. The growing periods to harvest were ranged from 25-50 days and the sowing month was from April to November.

\section{Materials and methods}

\subsection{Chemicals and seeds}

Phenol of analytical grade was purchased from Guangzhou Luo Xin Bao Chemicals Ltd., and 2,4,6-trichlorophenol (TCP) of purity $>97.0 \%$ (GC) were 
purchased from Sigma-Aldrich. Seeds were purchased from Guangzhou Changhe Seed Co. Ltd. Six different local agricultural plant species were tested. They included 1) Amaranthus mangostanus "Round-leaf green amaranth" (Amaranthus); 2) Cucumis melo var. conomon Makino "oriental pickling melon long-body green strips"(Cucumis); 3) Raphanus sativus "short-leave radish no.13"(Raphanus); 4) Brassica Campestris ssp. Chinensis var. utilis "AprilSeptember flowering Chinese cabbage no.19" ("Cabbage no.19"); 5) Brassica Campestris ssp. Chinensis var. utilis "yellow-leaf medium flowering Chinese cabbage" ("Yellow leaf cabbage"); 6) Brassica campestris ssp. Chinensis Makino var. communis "Pak Choi" ("Pak Choi"). The six agricultural species used in the present studies are the popular Chinese vegetables in Guangdong province of southern China. The growth cycle of these agricultural species take average of 25-50 days and the sowing months are usually around summer to autumn from April to October (Table 1). The appearances of the six seeds are similar to each other. They are small and round, except Raphanus and Cucumis with bigger seeds (Table 1). The toxicity test model of seed germination and root elongation [14] was used in the present studies.

Table 1: $\quad$ Seed characteristics and planting practices of different species.

\begin{tabular}{|c|c|c|c|c|}
\hline & Seed Characteristics & \multicolumn{2}{|c|}{ Planting } \\
\cline { 2 - 5 } & Shape & $\begin{array}{c}\text { Diameter } \\
(\mathrm{mm})\end{array}$ & $\begin{array}{c}\text { Harvest } \\
\text { Time } \\
\text { (days) }\end{array}$ & $\begin{array}{c}\text { Sowing } \\
\text { month }\end{array}$ \\
\hline $\begin{array}{c}\text { Amaranthus mangostanus "Round-leaf green } \\
\text { amaranth" }\end{array}$ & Round & 1.5 & $25-30$ & $4-10$ \\
\hline $\begin{array}{c}\text { Cucumis melo var. conomon Makino "oriental } \\
\text { pickling melon long-body green strips" }\end{array}$ & Oval & $3 \times 7$ & 35 & $3-4$ \\
\hline $\begin{array}{c}\text { Raphanus sativus "short-leave radish no.13" } \\
\text { Brassica Campestris ssp. Chinensis var. utilis "April } \\
\text { September flowering Chinese cabbage no.19"; }\end{array}$ & Round & 3.5 & 45 & 4,9 \\
\hline $\begin{array}{c}\text { Brassica Campestris ssp. Chinensis var. utilis } \\
\text { "yellow-leaf medium flowering Chinese cabbage"; }\end{array}$ & Round & 1.5 & $28-32$ & $5-10$ \\
\hline $\begin{array}{c}\text { Brassica campestris ssp. Chinensis Makino var. } \\
\text { communis "Pak Choi"; }\end{array}$ & Round & 1.5 & $40-50$ & $6-10$ \\
\hline
\end{tabular}

\subsection{Pretreatment of seeds}

Seeds were first pretreated with $10 \%$ sodium hypochlorite solution for 10 minutes, and soaked for 1 hour in glass-distilled water before air-dried at room temperature to remove the fungal spores.

\subsection{Seed germination and root elongation studies}

For the first part of the experiment, suitable incubation times for seed of each species were determined. Seed was incubated in the dark until at least 65 percent of the control seed have germinated and developed roots that were at least $20 \mathrm{~mm}$ long. The root length was measured from the transition point between the hypocotyls and to the tip of the root. For seed to be counted as having germinated, the length of the primary root should attain a length of $5 \mathrm{~mm}$. 
Using the optimal incubation time, the seeds were incubated in different concentration of test chemicals. Forty-five seeds per species were used for each exposure of different chemical concentration and control. Every 15 seeds were placed in a $15-\mathrm{mm}$ diameter petri dish with filter paper put in the bottom; $10 \mathrm{ml}$ of deionized water or chemical solution were used in each petri dish for seed germination and root elongation experiments. The petri dishes were then covered and incubated in the seed germinator at $25 \pm 1{ }^{\circ} \mathrm{C}$ and $75 \%$ humidity in complete darkness. Three replicates were repeated for each concentration. After the incubation, the root length of each seed was measured. Using probit transformation of a dose-response curve, the value of $\mathrm{EC}_{50}$ and $\mathrm{EC}_{30}$ of each chemical for each seed species were estimated.

\section{Results}

\subsection{TCP}

Figure 1a showed that TCP did not significantly affect the seed germination rate of Raphanus, Cucumis and Amaranthus. For the three species from the genus Brassica (Figure 1b), only the two species of "Pak Choi" and "Yellow leaf cabbage" were affected, but not the "Cabbage no.19". The seed germination rate was decreased with increased in TCP concentration. TCP was

Table 2: $\quad$ Effective concentration of TCP and Phenol for each species.

\begin{tabular}{|c|c|c|c|c|c|}
\hline & \multirow{2}{*}{$\begin{array}{r}\text { Incubation } \\
\text { Time (h) }\end{array}$} & \multicolumn{2}{|c|}{ TCP } & \multicolumn{2}{|c|}{ Phenol } \\
\hline & & $\begin{array}{l}\mathrm{EC}_{50} \\
\mathrm{ppm}\end{array}$ & $\begin{array}{l}\mathrm{EC}_{30} \\
\mathrm{ppm}\end{array}$ & $\mathrm{EC}_{50} \mathrm{ppm}$ & $\begin{array}{l}\mathrm{EC}_{30} \\
\mathrm{ppm}\end{array}$ \\
\hline $\begin{array}{c}\text { Amaranthus mangostanus } \\
\text { "Round-leaf green } \\
\text { amaranth" }\end{array}$ & 63 & 17.8 & 2.6 & 52.1 & 15.7 \\
\hline $\begin{array}{c}\text { Cucumis melo var. conomon } \\
\text { Makino "oriental pickling } \\
\text { melon long-body green } \\
\text { strips" }\end{array}$ & 61 & 14.9 & 5.0 & 322.7 & 139.8 \\
\hline $\begin{array}{l}\text { Raphanus sativus "short- } \\
\text { leave radish no.13" }\end{array}$ & 45 & 15.9 & 11.4 & 140.0 & 85.3 \\
\hline $\begin{array}{l}\text { Brassica Campestris ssp. } \\
\text { Chinensis var. utilis "April } \\
\text { September flowering } \\
\text { Chinese cabbage no.19"; }\end{array}$ & 60 & 15.3 & 4.8 & 42.7 & 31.0 \\
\hline $\begin{array}{l}\text { Brassica Campestris ssp. } \\
\text { Chinensis var. utilis } \\
\text { "yellow-leaf medium } \\
\text { flowering Chinese } \\
\text { cabbage"; }\end{array}$ & 60 & 9.7 & 3.4 & 67.5 & 28.4 \\
\hline $\begin{array}{l}\text { Brassica campestris ssp. } \\
\text { Chinensis Makino var. } \\
\text { communis "Pak Choi"; }\end{array}$ & 60 & 10.1 & 3.4 & 46.7 & 27.1 \\
\hline Literature value [5] & & 12.7 & & 125.6 & \\
\hline Benchmark value [1] & & & 10 & & 10 \\
\hline
\end{tabular}



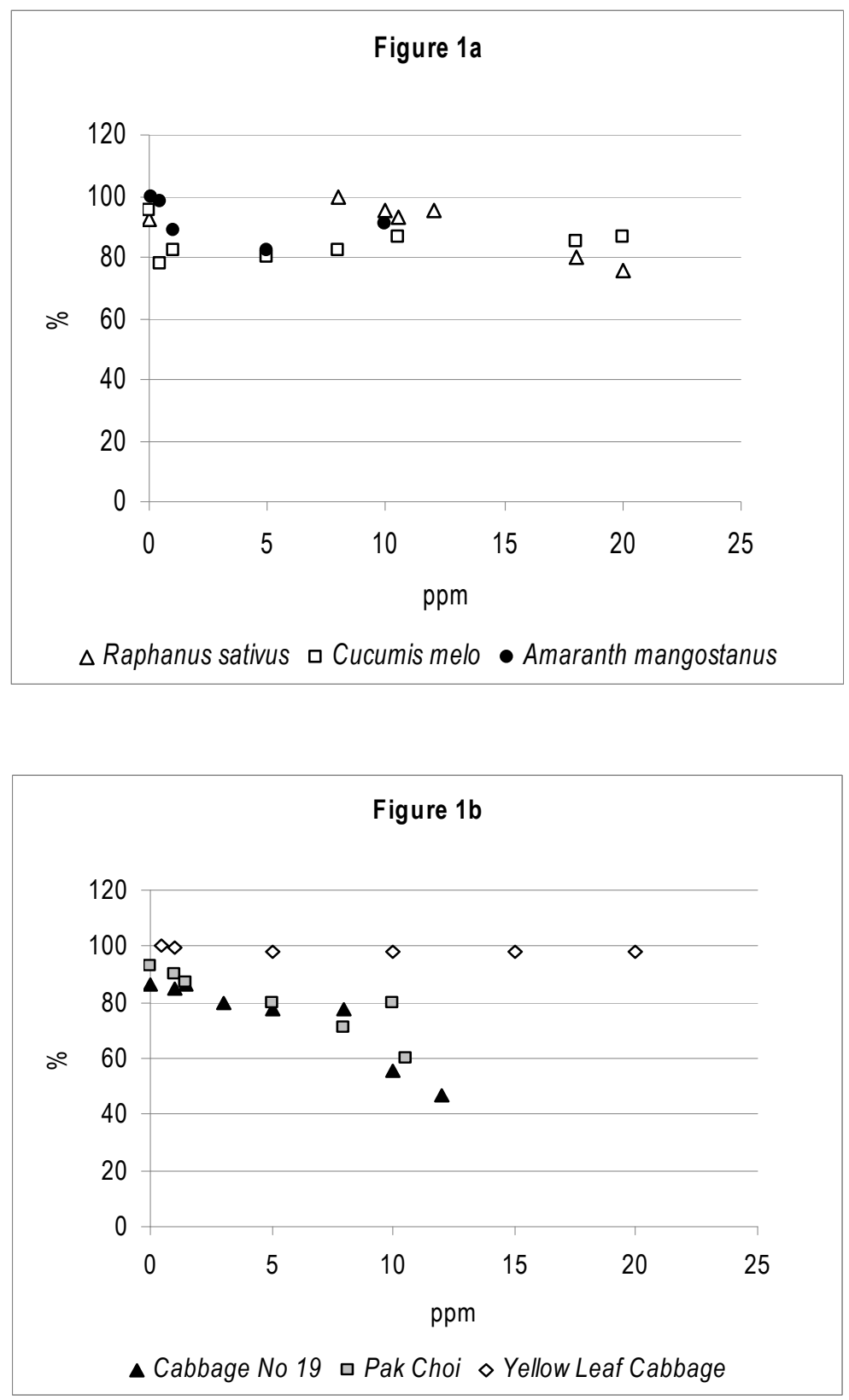

Figure 1: Seed germination rate at different TCP concentration. 

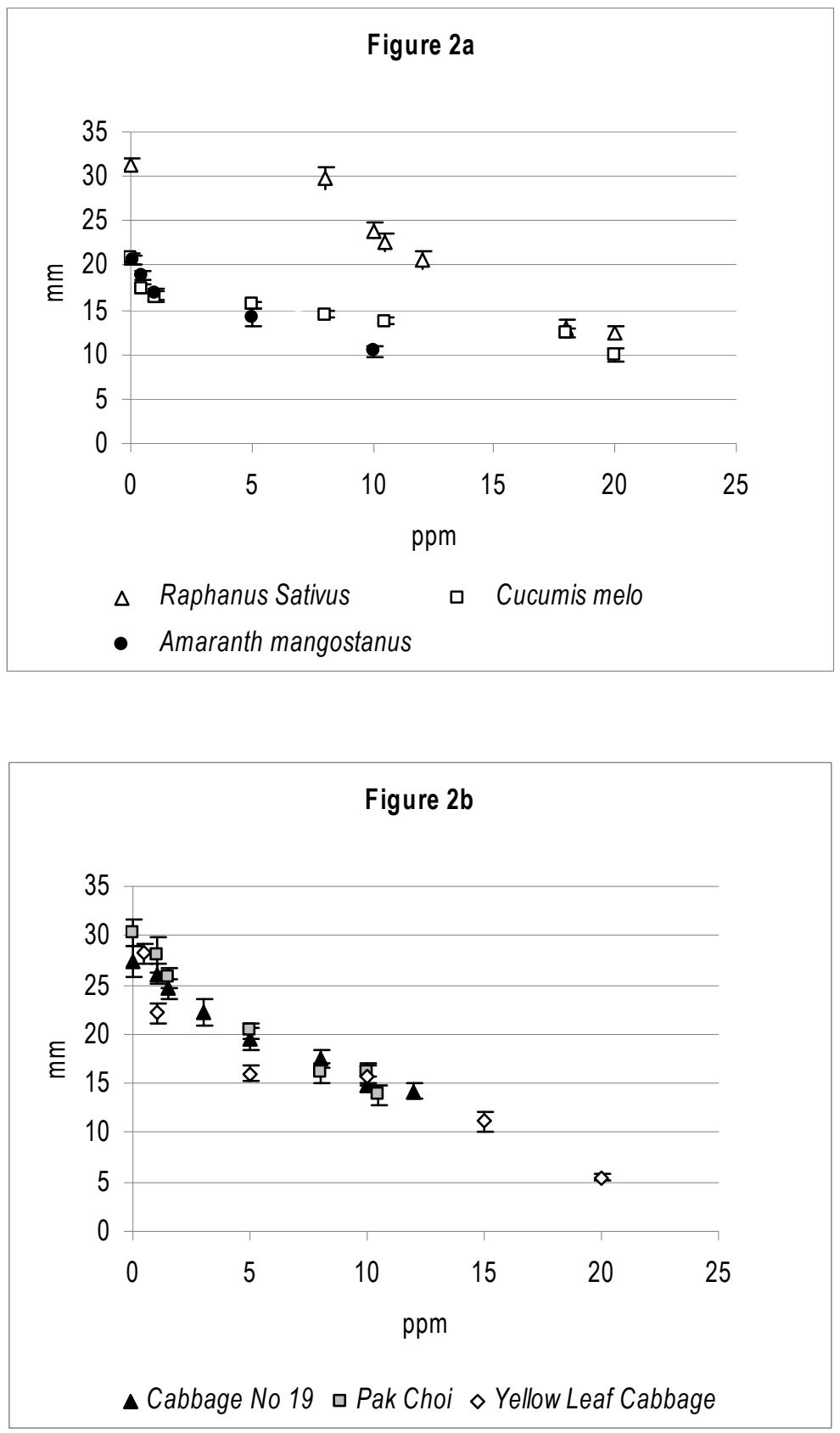

Figure 2: $\quad$ Root length at different TCP concentration. 

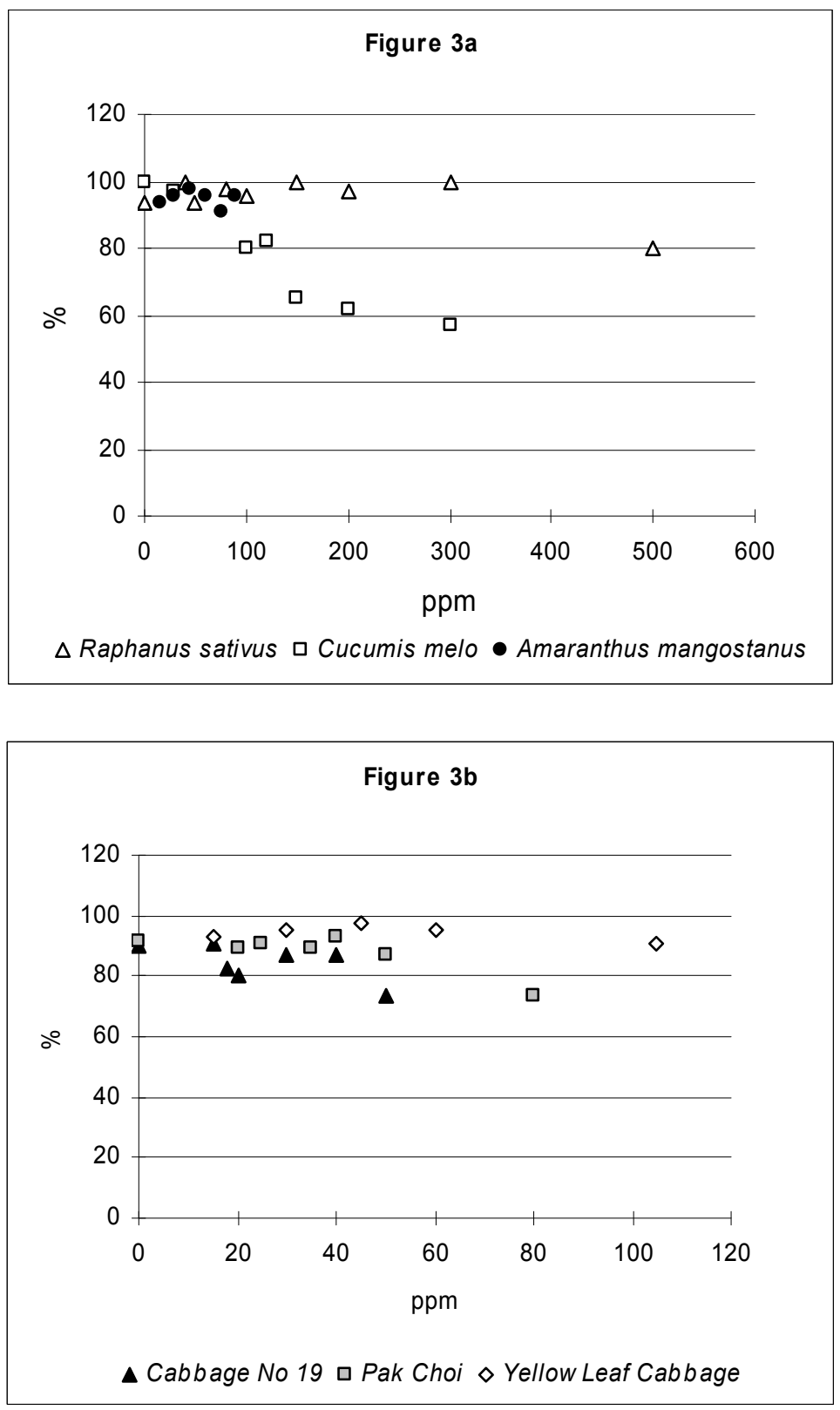

Figure 3: Seed germination rate at different Phenol concentration. 

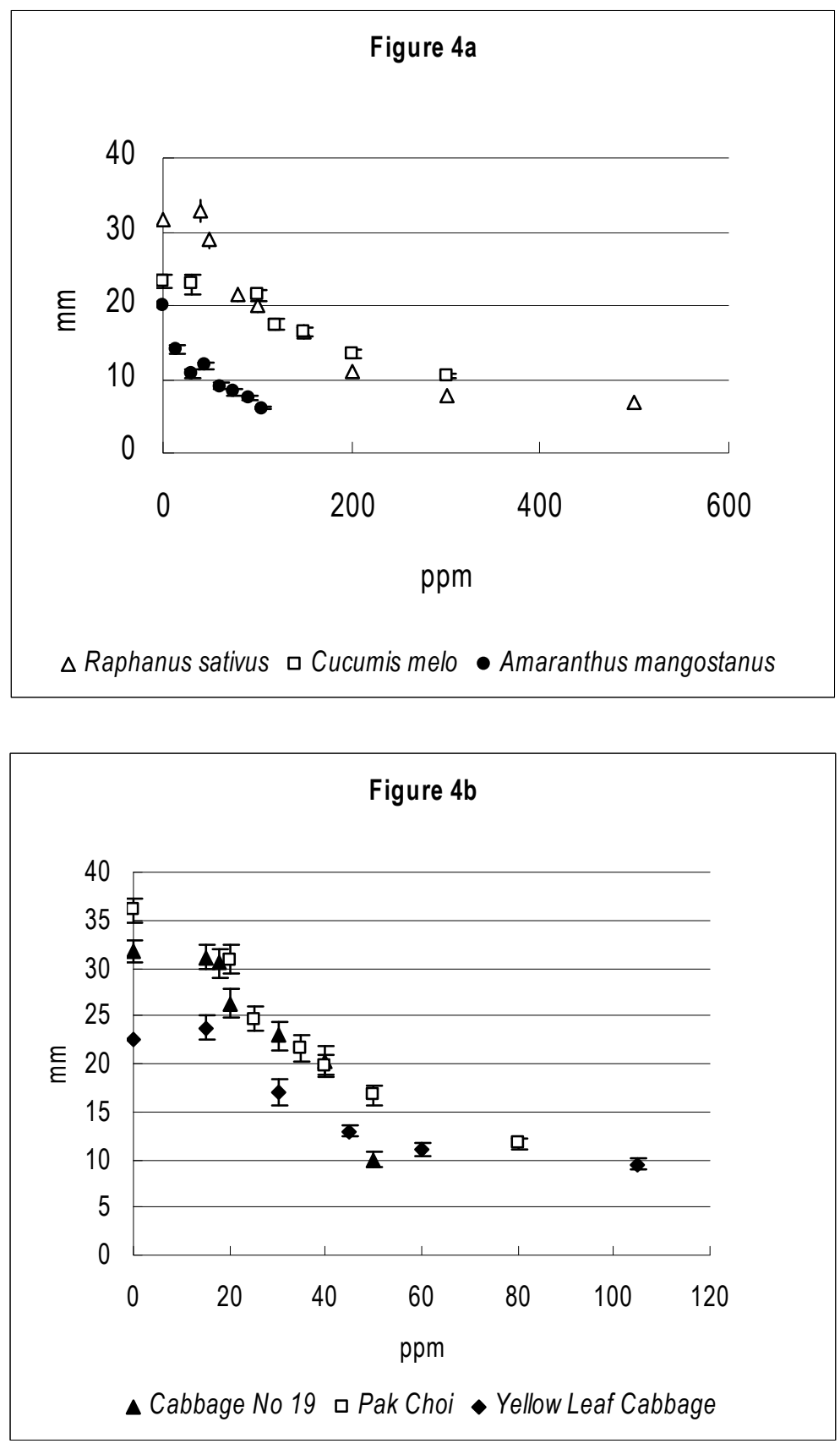

Figure 4: Root length at different Phenol concentration. 
found to reduce the root elongation of six species (Figure 2a, b). The higher the concentration of TCP was, more was the root length reduction. Table 2 showed that the $\mathrm{EC}_{50}$ of six plant species were comparable in values. For the $\mathrm{EC}_{30}$ of six species, Raphanus had the highest values, while Amaranthus had the lowest.

\subsection{Phenol}

Increased in Phenol concentration decreased the seed germination rate of Cucumis (Figure 3a), but not affecting the other five species (Figure 3b). Phenol was shown to reduce the root elongation of all six species in a concentration dependent manner (Figure 4a, b). However, at low concentration of Phenol, the growth of Raphanus was not dramatically affected (Figure 4a, b). Table 2 showed that Cucumis had the highest $\mathrm{EC}_{50}$ of $322.7 \mathrm{ppm}$ and seconded by Raphanus with $\mathrm{EC}_{50}$ of $140 \mathrm{ppm}$. For the other four species, the values of $\mathrm{EC}_{50}$ were ranged from 42.7 to $67.5 \mathrm{ppm}$. For $\mathrm{EC}_{30}$, Cucumis had the highest values, followed by Raphanus, and Amaranthus had the lowest. For the three species in genus Brassica, "Pak Choi", "Cabbage no.19" and "Yellow leaf cabbage", they had comparable values.

\section{Discussion}

Chinese food culture and the choice of vegetables were different from that of western society. The research data on Chinese agricultural species gradually become important, especially for ecological risk assessment in local area. The six agricultural species used in the present studies were the popular Chinese vegetables in Guangdong province of southern China. The growth cycle of these agricultural species took average of 25-50 days and the sowing months were usually around summer to autumn from April to October (Table 1). The appearances of the six seeds were similar to each other. They were small and round, except Raphanus and Cucumis with bigger seeds (Table 1). The six species also had comparable germination time. They all were shown to have high sensitivity to TCP, in particular for Amaranthus, and so its $\mathrm{EC}_{50}$ and $\mathrm{EC}_{30}$ were the smallest amongst the six species in studies. When compared this value to the toxicological benchmark concentration, the smallest value observed in six Chinese vegetables was only about one forth of the benchmark [1]. The deviation may suggest a readjustment of the benchmark may be necessary for Chinese vegetables.

For Phenol, the smallest $\mathrm{EC}_{30}$ shown by Amaranthus was comparable with the toxicological benchmark concentration [1]. Generally, the $\mathrm{EC}_{30}$ of the six agricultural species were much larger than that of TCP. It indicated that TCP was more toxic than Phenol to the growth of plants. The observation was consistent to the previous studies that addition of chlorine group in the Phenol increased its toxicity to plants [4]. Cucumis with the largest seed had the largest $\mathrm{EC}_{50}$ of $322.7 \mathrm{ppm}$ and followed by the second large seed Raphanus with $\mathrm{EC}_{50}$ of $140 \mathrm{ppm}$. Larger the seed was, less sensitive was to the chemicals. Larger seed may correlate with their higher capability to neutralize the toxic chemicals, 
possibly via the various mechanisms of degrading the toxic chemicals $[3,15-$ 17]. Although we did not observe a similar correlation in the studies with TCP, it could be due to the fact that TCP was much more toxic than phenol and so the differential tolerance of the seed could not be observed.

Although Cucumis had the largest $\mathrm{EC}_{50}$, but it was the only one species among the tested species was affected by Phenol in seed germination. For Raphanus, the seed with the second largest $\mathrm{EC}_{50}$ and $\mathrm{EC}_{30}$ values, the growth was not affected at low concentration of Phenol. The root maintained a similar growth rate at the low concentration and declined only after the threshold concentration was reached (Figure 4a). A similar growth pattern was observed for Raphanus exposed to TCP (Figure 2a). When considering both impact factors of seed germination and root elongation, Raphanus was considered to be the most tolerant species among the six to the effect of Phenol. It also applied to TCP that Raphanus was also the most tolerant species.

For the three species chosen from the same genus Brassica, they were distinct in features and were treated as unique vegetables from the consumers' point of view. Their responses shown in growth inhibition to both chemicals were similar, but their responses in seed germination were different. "Cabbage no.19" and "Pak Choi" were inhibited by TCP in seed germination, but not "Yellow leaf cabbage". As there were differential responses to chemicals even within the close family, it may be worth to study more on other close species. Chinese agricultural plants were unique and may respond differently from that of the western countries. It was supported by the present studies to show the differential sensitivity to contaminant. It would be worthwhile to investigate more on Chinese agricultural plants upon the exposure to other types of environment contaminants.

\section{Acknowledgement}

This work was financially supported by UIC Research Grant.

\section{References}

[1] Efroymson, R.A., Will, M.E., Suter, II G.W., Wooten, A.C. Toxicological Benchmarks for Screening Contaminants of Potential Concern for effects on Terrestrial Plants: 1997 Revision Oak Ridge National Laboratory, Oak Ridge TN, 1997

[2] Agency for Toxic Substances and Disease Registry (ATSDR). Toxicological Profile for Phenol (Update). Public Health Service, U.S. Department of Health and Human Services, Atlanta, GA, 1998

[3] Biswas, D. K., Scannell, G., Akhmetov, N., Fitzpatrick, D., Jansen, M. AK. 2,4,6-Trichlorophenol mediated increases in extracellular peroxidase activity in three species of Lemnaceae Aquatic Toxicology 100: 289-294, 2010 
[4] Michałowicz, J., Majsterek, I. Chlorophenols, chlorocatechols and chloroguaiacols induce DNA base oxidation in human lymphocytes (in vitro). Toxicology 268(3): 171-175, 2010

[5] Feng, L., Wang, L., Zhao, Y. and Song, B. Effects of substituted anilines and phenols on root elongation of cabbage seed. Chemosphere 32: 15751583,1996

[6] van Gestel, C.A.M., Adema, D.M.M., and Dirven-van Breemen, E.M. Phytotoxicity of some chloroanilines and chlorophenols, in relation to bioavailability in soil. Water, Air Soil Pollut. 88:119-132, 1996

[7] Hulzebos, E.M., Adema, D.M.M., Dirven-van Breemen, E.M., Henzen, L., van Dis, W.A., Herbold, H.A., Hoekstra, J.A., Baerselman, R., and van Gestel, C.A.M. Phytotoxicity studies with Latuca sativa in soil and nutrient solution. Environ. Toxicol. Chem. 12:1079-1094, 1993

[8] Gupta, S., Satpati, S., Nayek, S., Garai, D. Effect of wastewater irrigation on vegetables in relation to bioaccumulation of heavy metals and biochemical changes Environmental Monitoring and Assessment 165:169177,2010

[9] Gupta, S., Satpati, S., Nayek, S., Garai, D. Effect of wastewater irrigation on vegetables in relation to bioaccumulation of heavy metals and biochemical changes Environmental Monitoring and Assessment 165:169177,2010

[10] Ogunniyi, TAB., Oni, PO., Juba, A., Asaolu, SO., and Kolawole, DO. Disinfectants/antiseptics in the management of guinea worm ulcers in the rural areas. Acta Tropica 74: 33-38(6), 2000 doi:10.1016/S0001706X(99)00057-1

[11] "Safety data for 2,4,6-trichlorophenol". University of Oxford. 2005-09-05. http://physchem.ox.ac.uk/MSDS/TR/2,4,6-trichlorophenol.html.

[12] Hazardous Substances Data Base. National Library of Medicine. http://toxnet.nlm.nih.gov/HSDB

[13] Media release 9/2006: Metals in china: protecting the environment. Reference 06/177 http://www.csiro.au/news/ps291.html

[14] EPA OPPTS 850.4200 Ecological effects test guidelines. Seed germination/ root elongation toxicity test

[15] Aranda, E., Sampedro, I., Ocampo, JA., Garcia-Romera, I. Phenolic removal of olive-mill dry residues by laccase activity of white-rot fungi and its impact on tomato plant growth International Biodeterioration \& Biodegradation 58:176-179, 2006

[16] Singh, S., Melo, JS., Eapen, S., D’Souza, SF. Potential of vetiver (Vetiveria zizanoides L. Nash) for phytoremediation of phenol Ecotoxicology and Environmental Safety 71: 671-676, 2008

[17] Saparrat, MCN., Jurado, M., Díaz, R., Romera, I.G., Martínez, M.J. Transformation of the water soluble fraction from "alpeorujo" by Coriolopsis rigida: the role of laccase in the process and its impact on Azospirillum brasiliense survival. Chemosphere 78(1):72-76, 2010 